\title{
INFLUENCE OF SURROUNDING BOUNDARIES ON FIRE COMPARTMENT TEMPERATURE
}

\author{
Alexandra Byström, Ulf Wickström \\ Luleå University of Technology, Department of Civil, Environmental and Natural Resources Engineering, Luleå, \\ Sweden
}

\begin{abstract}
This paper shows and demonstrates how an analysis of the energy and mass balance of a fully developed (ventilation controlled) compartment fire can be used as a basis for simple and accurate predictions of fire temperatures. The model has been applied on compartments of light weight concrete structures. A finite element FE analysis has been used to solve the heat transfer equation. Effects of moisture were considered for material properties of the surrounding structure. The results were validated with experiments. The model then accurately predicted the fire temperatures and among other things it showed the influence of moisture in the surrounding structure on the fire temperature. Parametric temperature curves according to EN 1991-1-2, 2002 were shown to overestimate the fire temperature.
\end{abstract}

Keywords: post-flashover fire, room fire temperature, light weight concrete.

\section{INTRODUCTION}

Based on the work of Magnusson and Thelandersson (Magnusson and Thelandersson, 1970), Wickström (Wickström, 1985) proposed a modified way of expressing fully developed design fires based on the standard ISO 834 time-temperature curve. These were later adapted by the Eurocode EN 1991-1-2 as the so called parametric fire curves. The thermal properties of the compartment boundaries are then expressed as the thermal inertia. They will have a profound influence on the fire temperature development. The higher inertia, the slower temperature development rate. In other words, when the surrounding structures are made of light insulating materials, the maximum fire temperature is reached faster than if surrounded by heavy materials like concrete.

The temperature development as a function of time may in some idealized cases be calculated by a simple analytical closed form expression (Wickström \& Byström, 2014; Evegren \& Wickström, 2015). With numerical analyses using ordinary finite elements codes for temperature calculations this new way of modelling may be applied to surrounding structures of various compositions. Thus structures consisting of several layers and even voids as well as materials with properties varying with temperature may be considered (Byström, 2013).

\section{BACKGROUND}

\subsection{Heat balance of fully developed compartment fire}

The heat balance of any compartment fire can be written as:

$$
\text { (Heat release rate by combustion })=\sum(\text { Heat loss rate })
$$

Thus the heat balance for a fully developed fire compartment as shown in Figure 1 may be written:

$$
\dot{q}_{c}=\dot{q}_{l}+\dot{q}_{w}+\dot{q}_{r}
$$

where $\dot{q}_{c}$ is the heat release rate in the compartment by combustion of fuel, $\dot{q}_{l}$ the heat loss rate due to the flow of hot gases out of the compartment openings, $\dot{q}_{w}$ the losses to the compartment 
boundaries and $\dot{q}_{r}$ is the heat radiation out through the openings. Other components of the heat balance equation are in general insignificant and not included in a simple analysis as this.

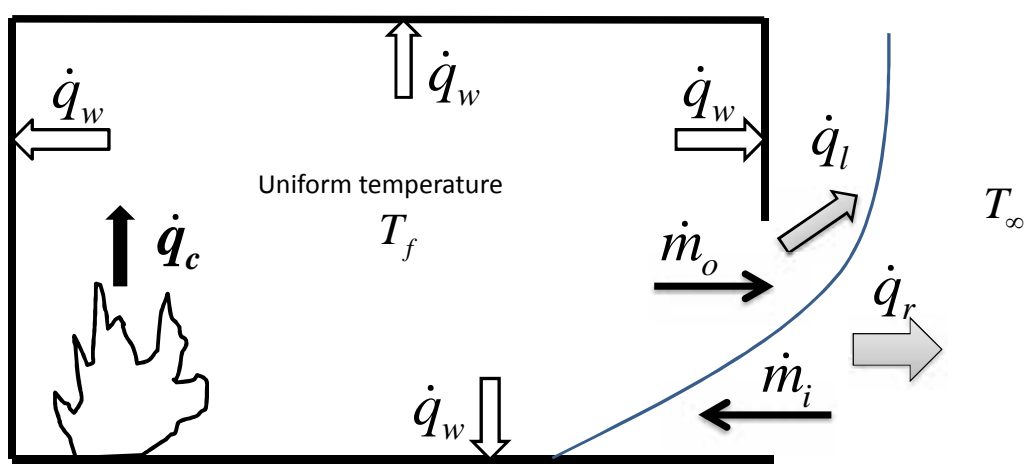

Fig. 1 Heat balance for the post-flashover compartment fire.

\subsection{Wickström \& Byström model}

The new simple calculation method for compartment temperatures has been discussed early in (Wickström \& Byström, 2014). This model is applicable to post-flashover compartment fires, i.e. for ventilation controlled fires (a uniform gas temperature is assumed) and even can be used for preflashover fire in enclosures where the heat capacity is lumped into the core of the surrounding structure (Evegren \& Wickström, 2015).

It is based on energy and mass balance of the fire compartment as indicated in Fig.1 applying conservation principles, which has been discussed in an earlier publication (Wickström and Byström, 2014). Thus equation 1 can be re-written as (Wickström, 2015):

$$
\dot{q}_{w}^{\prime \prime}=c_{p} \alpha_{1} O\left(\frac{\chi \alpha_{2}}{c_{p}}-\theta_{f}\right)+\frac{A_{o}}{A_{t o t}} \sigma\left(T_{\infty}^{4}-T_{f}^{4}\right)
$$

where $\chi$ is the combustion efficiency, $\alpha_{2}$ a constant describing the combustion energy developed per unit mass of air $\alpha_{2}=3.01 \cdot 10^{6} \mathrm{Ws} / \mathrm{kg}$, a $\alpha_{1} \approx 0.5 \mathrm{~kg} / \mathrm{m}^{2.5} \mathrm{~s}$ proportionality constant (called a flow constant), $c_{p}$ is the specific heat capacity of the combustion gases (usually assumed equal to that of air), $T_{f}, T_{i}$ and $T_{\infty}$ are the fire, initial and ambient temperatures, respectively, $\theta_{f}$ the fire temperature increase, $\theta_{f}=T_{f}-T_{i}$ and $\dot{q}_{w}^{\prime \prime}$ is the heat flux rate to the enclosure surfaces. This term contains the inertia of the system, see (Wickström \& Byström, 2014). Finally, $O$ is the so called opening factor defined as:

$$
O=A_{o} \sqrt{H_{o}} / A_{t o t}
$$

where $A_{o}$ and $H_{o}$ are the area and height of the opening, respectively, $A_{\text {tot }}$ is the total surrounding area of the enclosure. If the losses to the compartment boundaries, $\dot{q}_{w}^{\prime \prime}$, and the radiation losses through the openings, $\dot{q}_{r}^{\prime \prime}$, are negligible then the so called ultimate compartment fire temperature, $\theta_{u l t}$, (Wickström and Byström, 2014) can be reached, as follows from Eq.(3):

$$
\theta_{u l t}=\chi \alpha_{2} / c_{p}
$$

The parameter $\chi$ has a major effect on the value of ultimate temperature. In reality, it is hard to estimate the combustion efficiency in a real fire. That is why some assumptions should be made. For the analytical solution, the value of $\chi$ was assumed to be in the order of about $50 \%$ (Wickström 
\& Byström, 2014). For the numerical solution when the heat loss through the openings is taken into account, a higher value of combustion efficiency of $60 \%$ is assumed (Byström, 2013).

As we can see Eq. (3) is analogous to the heat transfer equation by convection between the gas and solid surface and the thermal conditions may be seen as the analogous electrical model, Fig. 2:

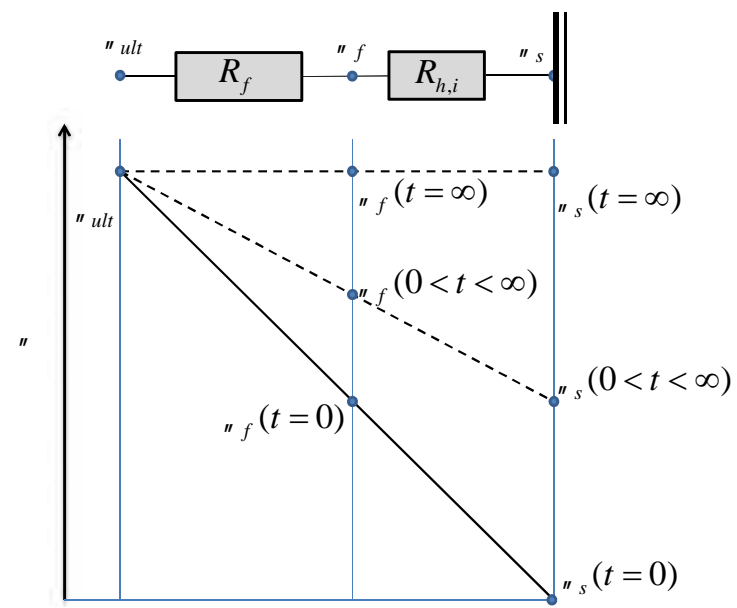

Fig. 2 Electrical analogy of the fire model for any structure. The indication of the temperature initially $(t=0)$, after some time $(0<t<\infty)$ and after a very long time $(t=\infty)$ is adapted from.

Based on the work described earlier (Wickström \& Byström, 2014; Byström, 2013) for the numerical analysis following equation, described mixed boundary conditions, have been used:

$$
\dot{q}_{w}^{\prime \prime}=\frac{1}{R_{h, i}+R_{f}}\left(\frac{\chi \alpha_{2}}{c_{p}}-\theta_{s}\right)+\frac{A_{o}}{A_{t o t}} \frac{1}{\left(1+\frac{R_{h, i}}{R_{f}}\right)} \sigma\left(T_{\infty}^{4}-T_{f}^{4}\right)
$$

where $R_{f}$ is an artificial thermal resistance here named the fire heat transfer resistance (read more in (Wickström \& Byström, 2014)) which is introduced as:

$$
R_{f}=\frac{1}{c_{p} \alpha_{1} O}
$$

and $R_{h, i}$ in the figure denotes the total heat transfer thermal resistance at the fire exposed surface (for the mixed boundary condition, i.e. both radiation, $h_{r a d}$, and convection heat transfer, $h_{c o n}$ ):

$$
R_{h, i}=\frac{1}{h_{i}}=\frac{1}{h_{\text {rad }}+h_{\text {conv }}}
$$

By rule of proportion, the fire temperature can be calculated depending on the calculated surface temperature and the ultimate temperature as:

$$
\theta_{f}=\frac{\theta_{s} R_{f}+\theta_{u l t} R_{h, i}}{R_{f}+R_{h, i}}
$$

Eq. (6) can be interpreted as a boundary condition for a structure exposed to radiation and convection where the heat transfer is expressed as:

$$
\dot{q}_{w}^{\prime \prime}=h^{*}\left(T_{u l t}-T_{s}\right)+\varepsilon^{*} \sigma\left(T_{\infty}^{4}-T_{f}^{4}\right)
$$

This theory will be used for the numerical analysis with following parameters, Table 1. 
Table 1 Analogue parameters

\begin{tabular}{|c|c|c|}
\hline Emissivity & Convection heat transfer coefficient & Ultimate fire temperature \\
\hline$\varepsilon^{*}=\frac{1}{R_{f}+R_{h, i}}=\left(\frac{1}{c_{p} \alpha_{1} O}+\frac{1}{h_{i}}\right)^{-1}$ & $h^{*}=\frac{A_{o}}{A_{t o t}}\left(1+\frac{R_{h, i}}{R_{f}}\right)^{-1}$ & $\theta_{u l t}+T_{i}=\frac{\chi \alpha_{2}}{c_{p}}+T_{i}$ \\
\hline
\end{tabular}

\subsection{EC 1991-1-2: Parametric fire}

According to EN 1991-1-2, the temperature-time curve in the heating phase in the compartment, can be written as:

$$
T_{f}=20+1325 \cdot\left(1-0.324 \cdot e^{-0.2 \cdot t^{*}}-0.204 \cdot e^{-1.7 \cdot t^{*}}-0.472 \cdot e^{-19 \cdot t^{*}}\right)
$$

where the dimensionless time, $t^{*}$, depends on the opening dimensions and compartment boundaries: the thermal conductivity, $k$; the density, $\rho$ and the specific heat capacity, $c$, i.e.:

$$
t^{*}=t \cdot \Gamma
$$

where time $t$ is in minutes. $\Gamma$ is named the time factor, a function of the opening factor $O$, given in Eq. 4), and the thermal inertia $\sqrt{k \rho c}$

$$
\Gamma=\left[\frac{O / \sqrt{k \cdot \rho \cdot c}}{0.04 / 1160}\right]^{2}
$$

\section{EXPERIMENTAL SETUP}

The experiments were conducted at the testing laboratory facility at SP Fire Research.

The structure which was representing an office room in scale 3:4 was built of light weight concrete with a thickness of $10 \mathrm{~mm}$. The real inner dimensions were $1800 \mathrm{~mm}$ in width and height and 2700 $\mathrm{mm}$ in length. Centrally on one of the short ends an opening representing a door was created with $1500 \mathrm{~mm}$ in height and $600 \mathrm{~mm}$ in width, Fig. 3.
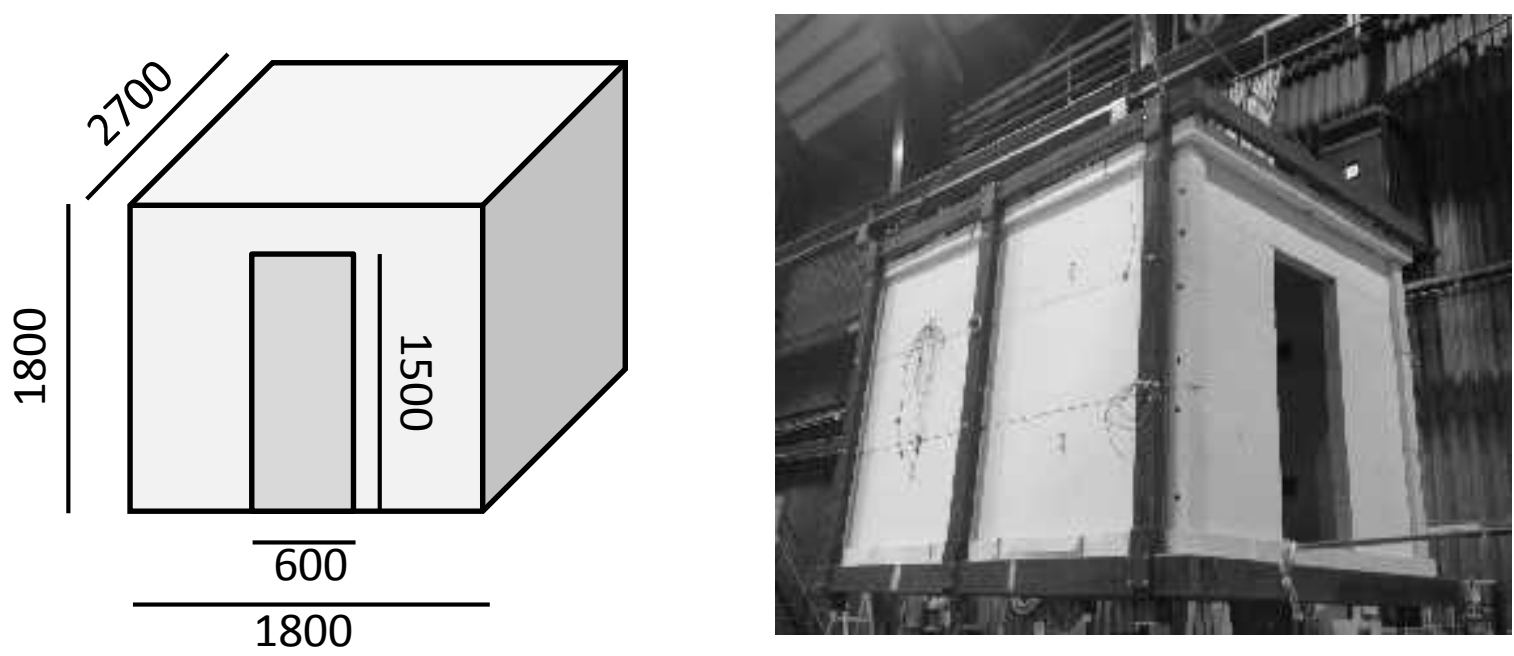

Fig. 3 To the left: inner dimensions of enclosure. To the right: of test object, enclosure with thickness of 100 mm lightweight concrete. 
A diffusion propane burner ( 300 by $300 \mathrm{~mm}$ ) was placed in the room. The gas inlet is through the wall close to the bottom and half the volume is filled with gravel $(\sim 10-20 \mathrm{~mm}$ stones). The heat release rate has been kept constant at $1000 \mathrm{~kW}$.

Two experiments have been selected and compared:

- The first experiment was conducted in the compartment with the structures containing its original moisture. The density of the material was measured before testing to be around 760 $\mathrm{kg} / \mathrm{m}^{3}$ containing $39 \%$ of moisture (dry basis by weight).

- The second experiment was conducted in the same compartment after, a series of fire experiments. So it can be assumed that the concrete had dried out.

More details for the original concrete as well as after exposure in a furnace of $105{ }^{\circ} \mathrm{C}$ during $24 \mathrm{~h}$ are found in Table 2.

Table 2 Thermal material properties of the lightweight concrete.

\begin{tabular}{|c|c|c|}
\hline Property & Original & Dry \\
\hline Specific heat $(\mathrm{J} / \mathrm{kgK})$ & 851 & 835 \\
\hline Thermal conductivity at room temperature $(\mathrm{W} / \mathrm{mK})$ & 0.330 & 0.166 \\
\hline
\end{tabular}

Several thermocouple trees were installed to measure gas temperatures. Standard Plate Thermometers together with thermocouples have been used both inside the compartment and in the door opening. In total more than 50 measuring devices were installed. In this paper only the highest measured temperature has been selected and compared with calculated temperature.

\section{NUMERICAL SOLUTION OF NEW ONE-ZONE FIRE MODEL}

The purpose of using finite element modelling is that we can include non-linear phenomena like the heat loss rate by radiation through vertical openings in the one dimensional heat transfer analysis as well as material properties varying with temperature. It also gives us the opportunity to predict fire compartment temperatures with different material layouts of the walls.

Due to the same material on all surrounded structures a one-dimensional heat transfer analysis was considered. For the analysis with various material of the celling, walls and floor, a two- or threedimensional $\mathrm{FE}$ analysis is required.

Assumptions:

- A combustion efficiency of $60 \%$ is assumed according to the theory above, Eq. (5)

- The heat transfer resistance between the fire gases and the exposed surface is kept at the constant value $R_{h, i}=1 / h_{i}=1 / 450\left[\mathrm{~m}^{2} \mathrm{~K} / \mathrm{W}\right]$ (see Eq. (8)), where the convection heat transfer coefficient is $h_{c o n}, 25\left[\mathrm{~W} / \mathrm{m}^{2} \mathrm{~K}\right]$ and radiation heat transfer coefficient, $h_{\text {rad }}=4 \varepsilon \sigma T_{r}^{3}$, for $T_{f}=T_{s}=1000\left[{ }^{\circ} \mathrm{C}\right]$.

- The heat transfer coefficient by convection on the unexposed side was assumed equal to 4 $\mathrm{W} / \mathrm{m}^{2} \mathrm{~K}$

- The emissivities of the light weight concrete surfaces were assumed equal to 0.9 both on exposed and the unexposed sides.

\section{$5 \quad$ RESULTS AND DISCUSSIONS}

Fire temperatures numerically calculated by using the new model have been compared with experimentally measured temperatures for two fire experiments conducted in the compartment with moist and dry light weight concrete boundaries, respectively. Good agreement with the measured values and calculated temperatures were obtained as shown in Fig. 4a). However, the temperatures calculated with EN 1991-1-2 overestimates fire temperature increase after 10 minutes of the experiment, see Fig 4b). 
Note that the effect of moisture evaporation on the temperature development is handled very accurately by numerical calculation, see Fig.4a). The moisture content makes the temperature development rate slower.



a) Experimental measured temperatures vs. calculated ones

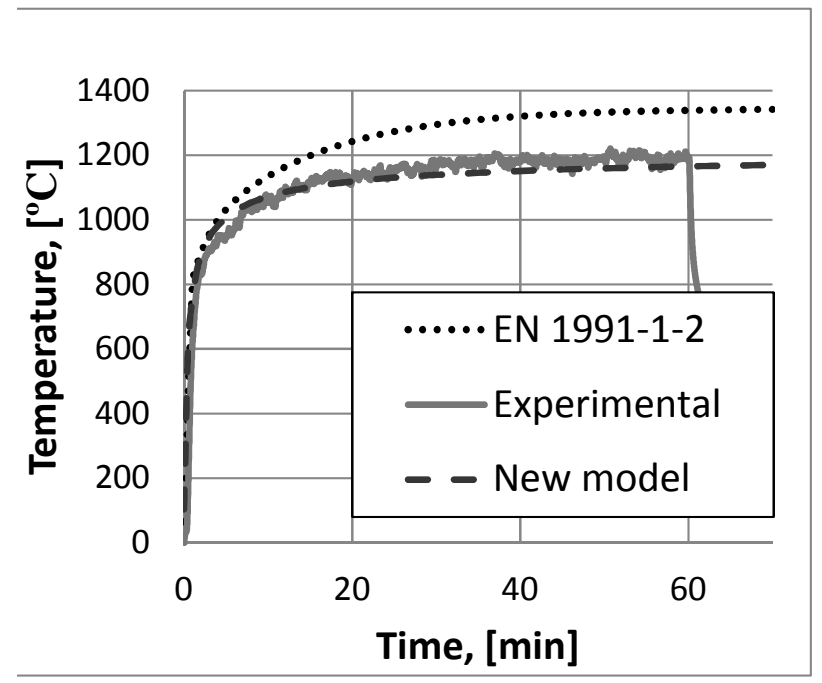

b) Dry concrete: experimental measured temperature vs. calculated with new model and EN 1991-1-2 ( $\Gamma=15.5$, Eq. (13))

Fig. 4 Comparison of calculated temperatures with measured higher temperature during experiments.

\section{CONCLUSIONS}

In this paper a new simple computational model has been validated with experiments conducted in a compartment of light weight concrete. The use of FE analysis gives the opportunity to very well predict fire temperature considering combinations of materials and non-linearities like material properties varying with temperature and moisture content (latent heat).

Some overall conclusions can be made:

- The fire temperature calculated with the new model is in good agreement with the highest measured temperatures

- The effects of moisture in the boundaries are handled very well by the numerical calculations

- The parametric fire temperature curve calculated according to EN 1991-1-2 overestimates the temperature increase in the case studied.

\section{ACKNOWLEDGMENTS}

I gratefully acknowledge the financial support provided by The Swedish fire research board, Brandforsk.

\section{REFERENCES}

Byström A., 2013. Fire temperature development in enclosures: some theoretical and experimental studies, Licentiate Thesis, Luleå University of Technology, Sweden.

Evegren F., Wickström U. 2015. New approach to estimate temperatures in pre-flashover fires: lumped heat case. Fire Safety Journal, 72, p. 77-86.

Magnusson S.,E., Thelandersson S., 1970. Temperature-Time Curves of Complete Process of Fire Development, ACTA Polytechnica Scandinavica, Civil Engineering and Building Construction Series No.65, Stockholm

Wickström U., 1985. Application of the Standard Fire Curve for Expressing Natural Fires for Design Purposes, Fire Safety: Science and Engineering, ASTM STP 882, American Society for Testing and Materials, Philadelphia, 145-159.

Wickström U., 2015. Draft: Heat transfer in fire technology, Luleå, Sweden, Luleå University of Technology.

Wickström U., Byström A., 2014. Compartment fire temperature: a new simple calculation method, in 11th International Symposium on Fire Safety Science, 10-14 February 2014, Christchurch, New Zealand. 